\title{
Caracterização morfofisiológica de isolados do gênero Cylindrocladium.
}

\author{
Christiane Ceriani Aparecido ${ }^{1, *}$, Edson Luiz Furtado² \& Mário Barreto Figueiredo ${ }^{1, * *}$
}

\begin{abstract}
${ }^{1}$ Centro de Pesquisas e Desenvolvimento de Sanidade Vegetal, Instituto Biológico, Av. Cons. Rodrigues Alves, 1252, CEP 04014-002, São Paulo, SP / ${ }^{2}$ Departamento de Produção Vegetal - FCA / UNESP, CP 237, CEP 18602-970, Botucatu / SP, e-mail: christianeceriani@biologico.sp.gov.br; *FAPESP - Bolsista de Doutorado (Proc. 01/13306-3); **Bolsista CNPq - Produtividade em Pesquisa

Parte da Tese de Doutorado do primeiro autor

Autor para correspondência: Christiane Ceriani Aparecido

Data de chegada:08/05/2006. Aceito para publicação em: 24/08/2007
\end{abstract}

\section{RESUMO}

Aparecido, C.C., Furtado, E.L. \& Figueiredo, M.B. Caracterização morfofisiológica de isolados do gênero Cylindrocladium. Summa Phytopathologica, v.34, n.1, p.38-47, 2008

Com o objetivo de caracterizar o "complexo" gênero anamórfico Cylindrocladium, dezoito isolados foram cultivados em meios de cultura distintos, mantidos sob diferentes temperaturas, além de ter conídios e vesículas terminais analisados morfologicamente para identificação correta das culturas. Inoculações em diferentes hospedeiros foram, também, realizadas para avaliação do comportamento patogênico dos isolados estudados. Com relação aos caracteres morfológicos, pôde-se observar que ocorrem alterações nas dimensões de conídios e na morfologia da vesícula terminal devido, provavelmente, à mudança do substrato de cultivo. Porém, a variabilidade natural nas características dessas estruturas é tão elevada que dificulta a identificação correta dos isolados. Em uma mesma cultura, por exemplo, foram observadas vesículas terminais de diferentes morfologias. Pôde-se constatar que existem diferenças patogênicas e fisiológicas entre os isolados, uma vez que houve a formação de grupos distintos quando tais características foram consideradas. Estas diferenças, provavelmente, sejam devidas à constituição genética distinta existente entre os isolados.

Palavras chave: Calonecria, eucalipto, caracteres morfológicos, fisiologia.

\section{ABSTRACT}

Aparecido, C.C., Furtado, E.L. \& Figueiredo, M.B. Morphophysiologic characterization studies of the genus Cylindrocladium. Summa Phytopathologica, v.34, n.1, p.38-47, 2008

In order to characterize the anamorphic genus Cylindrocladium eighteen isolates of this funguswere cultivated in different culture media, kept under different temperatures, besides having conidia and terminal vesicles morphologically analyzed for correct identification of the isolates. Inoculations on different hosts were carried out to evaluate of pathogenic behavior of the studied isolates. Concerning the morphologic characters studied, it was observed that alterations occurred in the conidial dimensions and morphology of the terminal vesicles, but was not important considering that is due to substratum changes. However, the natural variability in the general characteristics of these structures indicated that it is difficult to obtain a correct identification of the isolates. In the same culture it was observed terminal vesicles with different morphologies. Pathogenic and physiological differences among the isolates could be observed. This brings the idea of distinct population groups when such characteristics are considered in this study. These differences probably indicate a distinct genetic constitution among the isolates used in this study.

Additional keywords: Calonectria, Eucalyptus, morphologic behaviors, physiology.

A utilização de espécies florestais para produção de madeira, papel e celulose é muito importante no Brasil. Dentre os gêneros botânicos utilizados destacam-se o Pinus e o Eucalyptus. Porém, com a intensificação dos cultivos, inúmeros patógenos têm passado a parasitar as plantas, principalmente durante os estágios iniciais de desenvolvimento. Fungos do gênero Cylindrocladium têm se destacado como patógenos de Pinus e Eucalyptus, levando a problemas consideráveis em regiões tropicais e subtropicais, devido às condições ambientais favorecerem o desenvolvimento do patógeno, que pode causar morte das plantas mais jovens e, no caso de Eucalyptus, também a ocorrência de manchas foliares.

Diversas espécies de Cylindrocladium já foram detectadas no Brasil. O gênero foi descrito por Morgan em 1892, sendo a maioria patogênica a espécies florestais e culturas agronômicas de relevante importância $(2,3,4,5,10)$. A classificação taxonômica das espécies deste gênero está baseada em certos caracteres morfológicos que, de acordo com estudos, nem sempre se mostram confiáveis, uma vez que podem variar em função do substrato e de condições ambientais. Atualmente, além das espécies florestais, diversas espécies de plantas ornamentais têm sido infectadas. Por este motivo, a importância de Cylindrocladium spp. tem aumentado ainda mais.

Durante cerca de 20 anos, desde sua primeira constatação, o gênero Cylindrocladium afetava de forma mais expressiva espécies florestais. Porém, já em 1967, Figueiredo \& Namekata (21), detectaram e descreveram Calonectria quinqueseptata, fase teleomórfica de Cylindrocladium quinqueseptatum, sobre a 
espécie frutífera Annona squamosa (fruta do conde). Recentemente, também plantas ornamentais têm sido infectadas devido às condições ambientais do País (11). Em outros países da América, como Estados Unidos e, da Comunidade Européia, como Itália, França, Bélgica e Holanda, algumas espécies já foram constatadas tanto em plantas ornamentais como em outras culturas de importância econômica, pertencentes às mais variadas famílias botânicas $(14,18,39)$.

Segundo dados de literatura, o gênero Cylindrocladium agrupa 33 espécies $(1,14,31)$. A classificação taxonômica das espécies, geralmente, é realizada com base nos caracteres morfológicos de conídios (tamanho destas estruturas e número de septos) e no formato das vesículas terminais (30). Porém, alguns autores já identificaram variação na forma das vesículas dentro de um mesmo isolado, resultado este de variação no substrato e/ou idade da cultura e, por este motivo, talvez o este não seja um caracter muito confiável a ser considerado em estudos taxonômicos $(25,26,30)$. Quando cultivado em meio artificial, Cylindrocladium apresenta colônias de coloração marrom-castanha e de crescimento rápido, sob temperaturas elevadas (20). Atualmente, também a seqüência do DNA tem auxiliado nesta identificação $(16,29)$.

Observa-se, portanto, a necessidade de estudos relacionados a Cylindrocladium spp., patógeno que ganha importância devido à ampliação dos prejuízos econômicos que vem causando, como resultado da diversidade de hospedeiros que pode infectar. Assim, foram propósitos deste trabalho:

1)- avaliar a consistência das características morfológicas para a identificação de 18 isolados do gênero, quando cultivados em substratos distintos;

2)- verificar o comportamento fisiológico destes isolados através de inoculações cruzadas e do cultivo sob diferentes temperaturas.

\section{MATERIAL E MÉTODOS}

Foram utilizados os isolados relacionados na Tabela 1, provenientes de coleções existentes no Laboratório de Micologia Fitopatológica do Instituto Biológico de São Paulo, SP e no Departamento de Produção Vegetal da Faculdade de Ciências Agronômicas (FCA)-UNESP, Botucatu, SP. Todos os isolados estavam preservados pelo método de Castellani e foram testados previamente quanto à viabilidade e patogenicidade.

Para a caracterização morfológica dos isolados foram utilizados três diferentes meios de culturas: batata-ágar-dextrose (BDA - batata, 200 g; dextrose, 20 g; ágar, 17 g; água destilada, 1 L), Czapeck (meio sintético $-\mathrm{NaNO}_{3}, 3 \mathrm{~g} ; \mathrm{K}_{2} \mathrm{HPO}_{4} \cdot 7 \mathrm{H}_{2} \mathrm{O}, 0,5 \mathrm{~g} ; \mathrm{KCl}, 0,5 \mathrm{~g}$; $\mathrm{FeSO}_{4} .7 \mathrm{H}_{2} \mathrm{O}, 0,01 \mathrm{~g}$; sacarose, $30 \mathrm{~g}$; peptona, $1 \mathrm{~g}$; agar, $17 \mathrm{~g}$; água destilada, $1 \mathrm{~L}$ ) e GAA (Glucose-asparagina-ágar - glucose, $10 \mathrm{~g}$; asparagina, $2 \mathrm{~g}$; $\mathrm{K}_{2} \mathrm{HPO}_{4}, 1 \mathrm{~g} ; \mathrm{MgSO}_{4} \cdot 7 \mathrm{H}_{2} \mathrm{O}, 500 \mathrm{mg}$; $\mathrm{KCl}, 500 \mathrm{mg}$; ágar, $17 \mathrm{~g}$, água destilada, $1 \mathrm{~L}$ ), meio de cultura este que, de acordo com SINGLETON et al. (35) é excelente para o crescimento e esporulação de Cylindrocladium, além de outros fungos de solo.

Os isolados foram transferidos, separadamente, para placas de Petri contendo um dos meios e, assim que todo o diâmetro da placa foi tomado, foram preparadas lâminas para verificação da forma da vesícula terminal de cada isolado, medição do comprimento, largura e contagem do número de septos de vinte conídios, escolhidos ao acaso. Para a coloração das lâminas foi utilizado o corante azul de algodão com lactofenol. Posteriormente, foi calculada a média das dimensões, tanto para comprimento como para largura dos conídios medidos. Todas as observações foram realizadas sob microscópio scanner confocal MRC1024, com laser $\mathrm{Kr} / \mathrm{Ar}$ e documentadas através de digitalização das imagens. Os resultados obtidos com os meios de cultura utilizados foram comparados para constatar se diferentes substratos poderiam interferir nas características morfológicas de um mesmo isolado.

A caracterização fisiológica dos isolados foi realizada através de:

Tabela 1. Isolados do gênero Cylindrocladium utilizados no estudo.

\begin{tabular}{|c|c|c|}
\hline Isolado & Espécie & Hospedeiro \\
\hline IB223 & C. scoparium var. brasiliensis & E. alba \\
\hline IB239 & C. citri $^{*}$ & - \\
\hline IB268 & C. ilicicola & Eucalyptus sp. (estrangulamento da haste) \\
\hline IB328 & C. scoparium var. brasiliensis & Eucalyptus sp. \\
\hline IB421 & C. scoparium & Eucalyptus sp. \\
\hline IB5 15 & C.scoparium & Eucalyptus sp. \\
\hline IB728 & C. scoparium & Hevea brasiliensis (seringueira) \\
\hline IB $11 / 75$ & C. scoparium & Eucalyptus sp. \\
\hline IB6/78 & C. scoparium & E. urophylla (eucalipto) \\
\hline IB $12 / 79$ & C. clavatum & E. grandis (eucalipto) \\
\hline IB01/01 & C. spathiphylii & Spathiphyllum walisii (lírio da paz) \\
\hline FCA06 & Cylindrocladium sp. & Corymbia citriodora (eucalipto) \\
\hline FCA07 & Cylindrocladium sp. & Eucalyptus sp. (clones) \\
\hline FCA09 & Cylindrocladium sp. & Eucalyptus sp. (folhas) \\
\hline FCA 10 & Cylindrocladium sp. & Eucalyptus sp. \\
\hline $\mathrm{CKa}$ & Cylindrocladium $\mathrm{sp}$. & Kalanchoe sp. \\
\hline
\end{tabular}

${ }^{*}$ Centraal Bureau Voor Schimelcultures, Holanda 
A)-Inoculação dos isolados de Cylindrocladium diferentes hospedeiros (inoculações cruzadas)

Cada um dos isolados da Tabela 1 foi, separadamente, inoculado em solo esterilizado onde se desenvolviam mudas de E. urophylla e $E$. grandis, quando estas estavam com 20 dias de idade. Também, para as inoculações em solo esterilizado foi utilizada a planta ornamental denominada lírio-da-paz (Spathiphyllum wallisi Regel). As culturas utilizadas estavam com dez dias de idade e para as inoculações uma placa de cada isolado foi, separadamente, homogeneizada em liquidificador com $200 \mathrm{~mL}$ de água destilada. A seguir, uma alíquota 30 $\mathrm{mL}$ da suspensão obtida foi incorporada ao solo de cada vaso contendo uma planta. Ao tratamento controle foi incorporado $30 \mathrm{~mL}$ de uma suspensão resultante da homogeneização de meio BDA com água destilada. Para cada tratamento foram feitas seis repetições. Todos os tratamentos foram mantidos em casa de vegetação à temperatura ambiente $\left( \pm 27^{\circ} \mathrm{C}\right)$. A avaliação foi realizada pela observação dos sintomas característicos da doença, anotando-se, também, o número de dias decorrentes desde as inoculações até o aparecimento dos sintomas.

Com relação às inoculações sobre folhas, a uma placa de cada isolado foram adicionados $100 \mathrm{~mL}$ de água destilada e o micélio friccionado com alça de Drigalsky para liberação dos conídios. A suspensão preparada foi padronizada para a concentração de $10^{5}$ conídios $/ \mathrm{mL}$ e aspergida sobre ambas as faces das folhas de plântulas de E. urophylla e E. grandis, ambos com trinta dias de idade. Sobre as folhas das mudas do tratamento controle foi aspergida apenas água destilada. As plântulas foram cobertas com sacos plásticos umedecidos durante 24 h. Após esse período a câmara úmida foi removida e todos os tratamentos permaneceram em casa de vegetação, à temperatura ambiente $\left(27^{\circ} \mathrm{C}\right)$. Para a avaliação dos resultados, foram contadas todas as lesões dos três primeiros pares de folhas. Havendo o coalescimento de várias lesões, a mancha era considerada como uma única lesão. Após a contagem, o número total foi dividido pelo número de repetições, ou seja, seis plantas por tratamento.

Sendo observado resultado positivo, foi realizada a documentação fotográfica e uma planta de cada tratamento foi levada ao laboratório para reisolamento do patógeno para confirmar se os sintomas estavam sendo causados, de fato, pelo microrganismo inoculado.

B)-Coloração das colônias e crescimento em meio Czapeck

Cada isolado teve um disco de micélio+meio de cultura transferido, separadamente, para o centro de uma placa de Petri contendo o meio sintético Czapeck (37). A seguir, as placas foram mantidas em câmara do tipo BOD, a $25^{\circ} \mathrm{C}$, no escuro. As avaliações foram realizadas após 10 dias de incubação anotando-se o tipo e coloração do micélio e, realizando-se a medição do diâmetro de cada colônia em dois sentidos diametralmente opostos. Para cada isolado havia seis repetições. Os isolados semelhantes quanto ao tipo do micélio e coloração foram agrupados e os resultados foram documentados fotograficamente.

\section{C)- Crescimento dos isolados de Cylindrocladium em} diferentes temperaturas

Pequena porção de micélio+meio de cultura de cada isolado foi, separadamente, transferido para o centro de uma placa de Petri contendo o meio sintético Czapeck (37). A seguir, as placas foram mantidas em câmaras com temperatura controlada a $15^{\circ}, 20^{\circ}, 25^{\circ}, 30^{\circ}$ e $35^{\circ} \mathrm{C}$, no escuro. Foram realizadas duas avaliações: aos 7 e aos 10

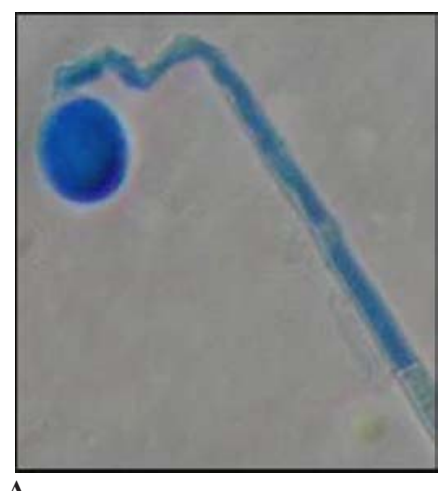

$\mathbf{A}$

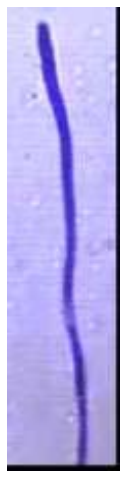

G

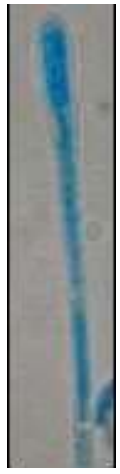

H

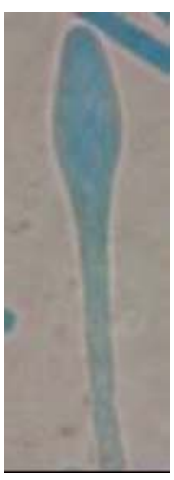

B

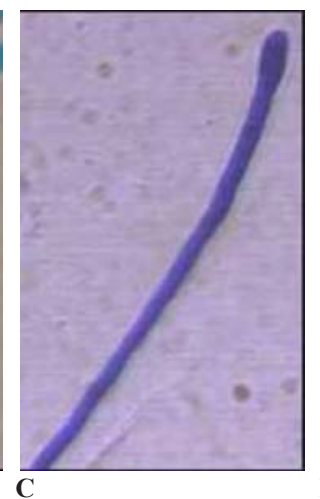

C
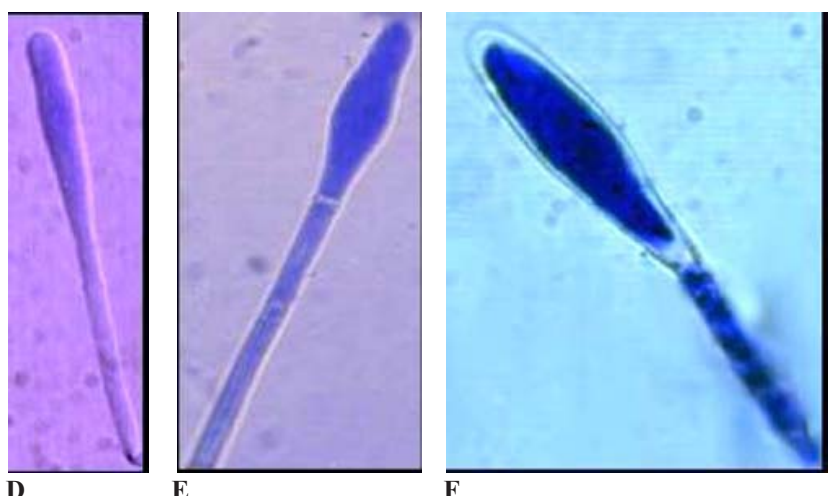

$\mathbf{E}$

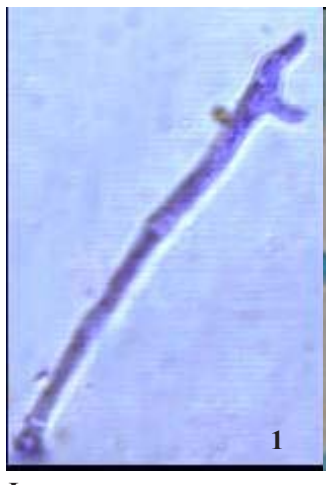

I

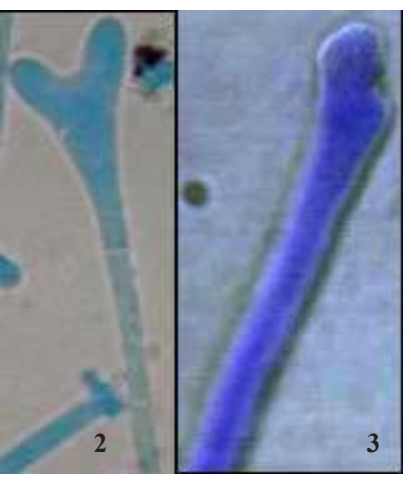

3

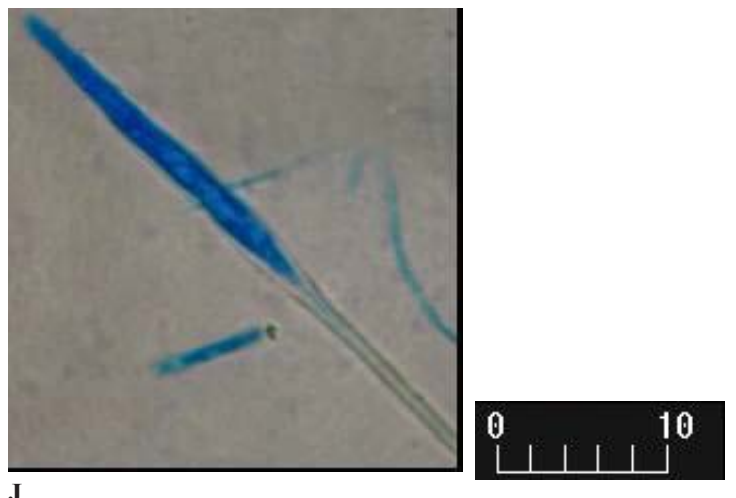

Figura 1. Formas das vesículas terminais observadas em Cylindrocladium spp. A $\rightarrow$ Globosa; B $\rightarrow$ Elipsoidal; C $\rightarrow$ Esferopedunculada; D $\rightarrow$ Clavada; E $\rightarrow$ Obpiriforme ou espatulada; F $\rightarrow$ Naviculada; $\mathrm{G} \rightarrow$ Aciculada; H $\rightarrow$ Estreitamente clavada; I $\rightarrow$ Disforme; J $\rightarrow$ Lanceolada. Aumento 100x (escala de barras $=10 \mathrm{Pm})$. 
dias de incubação, medindo-se o diâmetro de cada colônia em dois sentidos diametralmente opostos. Para cada isolado, a cada uma das diferentes temperaturas, havia três repetições. A documentação dos resultados foi realizada através da máquina fotográfica digital.

\section{RESULTADOS E DISCUSSÃO}

Caracterização morfológica dos isolados de Cylindrocladium

Constatou-se a existência de vesículas com diferentes formas, conforme ilustrado na Figura 1. É importante ressaltar que em qualquer dos meios de cultura utilizados (BDA, Czapeck ou GAA) a forma das vesículas terminais não foi modificada.

Deve-se ressaltar que, em um mesmo isolado, podem ocorrer vesículas com morfologia variada, o que dificulta a correta identificação das espécies. Resultados semelhantes foram observados em inúmeros estudos relativos ao gênero Cylindrocladium $(15,26,30)$. Segundo Peerally (31) e Crous at al. (15), a morfologia da vesícula terminal é influenciada pela idade da cultura e pelo potencial osmótico do meio de cultura, o que pode resultar na variabilidade morfológica dessa estrutura observada em um mesmo isolado.

Todos os conídios observados apresentavam-se cilíndricos, com ambas as extremidades arredondadas e variação de 1 a 3 septos. Alguns dos isolados não esporularam em Czapeck e / ou GAA. O isolado
IB239 esporulou em BDA somente após cerca de um mês, sem ser observada a formação de vesículas terminais. É possível que as características morfológicas desta cultura tenham sido alteradas devido ao tempo de armazenamento ou, ainda, pela incapacidade de metabolizar um ou mais nutrientes necessários à esporulação.

Com relação às culturas que esporularam, as dimensões dos conídios mostraram-se ligeiramente diferentes em cada substrato. Porém, é importante ressaltar que variações no comprimento e largura dos conídios podem ser observadas entre isolados e, também, no mesmo isolado. Isto pode ocorrer tanto quando se utiliza o mesmo substrato como quando são utilizados diferentes meios para o crescimento das colônias devido a diferenças na constituição genética de cada isolado $(8,14,26,30)$. Porém, tais variações quando pequenas são consideradas irrelevantes, caso estejam dentro da faixa de variação aceita para as espécies de Cylindrocladium (12).

Comparando-se conjuntamente a dimensão dos conídios e a morfologia das vesículas terminais com os dados de literatura, uma provável identificação das espécies estudadas foi elaborada (Tabela 2).

Observando-se a Tabela 2, verifica-se que, para alguns isolados, é possível identifica-los em mais de uma espécie, devido a grande variação nos caracteres morfológicos, conforme foi encontrado na literatura especializada. Por exemplo, em uma mesma espécie pode ser observada variação no formato da vesícula terminal, assim como

Tabela 2 - Espécies do gênero Cylindrocladium, identificadas com base na dimensão dos conídios e/ou forma da vesícula terminal.

\begin{tabular}{|c|c|c|c|c|}
\hline Isolado & Identificação Original & Identificação Morfológica & 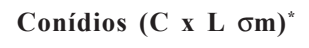 & Vesícula Terminal \\
\hline IB 12/79 & C. clavatum $($ C. gracile $)$ & C. gracile & $28,5-38,7 \times 3,5-4,2$ & Clavada \\
\hline FCA06 & Cylindrocladium sp. & C. gracile & $37,1-42,7 \times 3,4-4,2$ & Clavada \\
\hline IB239 & C. citri & C. leucothoes (sin. C. perseae) & $25,4-36,3 \times 1,9-3,1$ & -- \\
\hline IB268 & C. ilicicola & C. naviculatum & -- & Naviculada \\
\hline IB238 & C. scoparium & C. scoparium & $37,2-43,6 \times 2,5-3,6$ & Elipsoidal \\
\hline IB $11 / 75$ & C. scoparium & C. spathulatum & $40,1-46,9 \times 3,0-3,7$ & Obpiriforme ou Espatulada \\
\hline IB $17 / 89$ & C. scoparium & C. scoparium & $41,8-47,7 \times 4,1-5,2$ & Elipsoidal \\
\hline IB223 & C. scoparium var. brasiliensis & C. scoparium & $32,9-38,5 \times 2,2-3,9$ & Obpiriforme ou Espatulada \\
\hline FCA07 & Cylindrocladium sp. & C. scoparium & $37,4-44,4 \times 3,0-4,2$ & Elipsoidal a Espatulada ou Obpiriforme \\
\hline FCA10 & Cylindrocladium sp. & C. scoparium & $38,9-43,1 \times 3,6-4,3$ & Elipsoidal \\
\hline IB6/78 & C. scoparium & C. spathulatum & $37,0-44,2 \times 3,1-4,2$ & Obpiriforme ou Espatulada \\
\hline FCA09 & Cylindrocladium sp. & C. spathulatum & $42,4-50,0 \times 3,2-3,8$ & Obpiriforme ou Espatulada \\
\hline IB01/01 & C. spathiphylli & C. spathiphylli & $65,0-74,7 \times 4,2-5,6$ & Globosa \\
\hline IB42 1 & C. scoparium & Diversas & -- & Esferopedunculada \\
\hline IB515 & C. scoparium & Diversas & -- & Esferopedunculada \\
\hline IB728 & C. scoparium & Diversas & -- & Esferopedunculada \\
\hline IB328 & C. scoparium var. brasiliensis & Cylindrocladiella sp. & $16,0-19,3 \times 2,0-3,0$ & Clavada \\
\hline $\mathrm{CKa}$ & Cylindrocladium sp. & Cylindrocladiella sp. & $12,0-15,4 \times 1,6-2,0$ & Lanceolada \\
\hline
\end{tabular}

DIVERSAS: C. scoparium / C. parasiticum / C. quinqueseptatum / C. variabile. Cores iguais significam caracteres semelhantes, tratando-se, possivelmente, da mesma espécie. $(\square) \rightarrow$ não houve esporulação ou observação de vesícula terminal. *Dimensões obtidas pela medição de 20 conídios $(\mathrm{C}=$ comprimento $\mathrm{x} \mathrm{L}=$ largura $)$. 


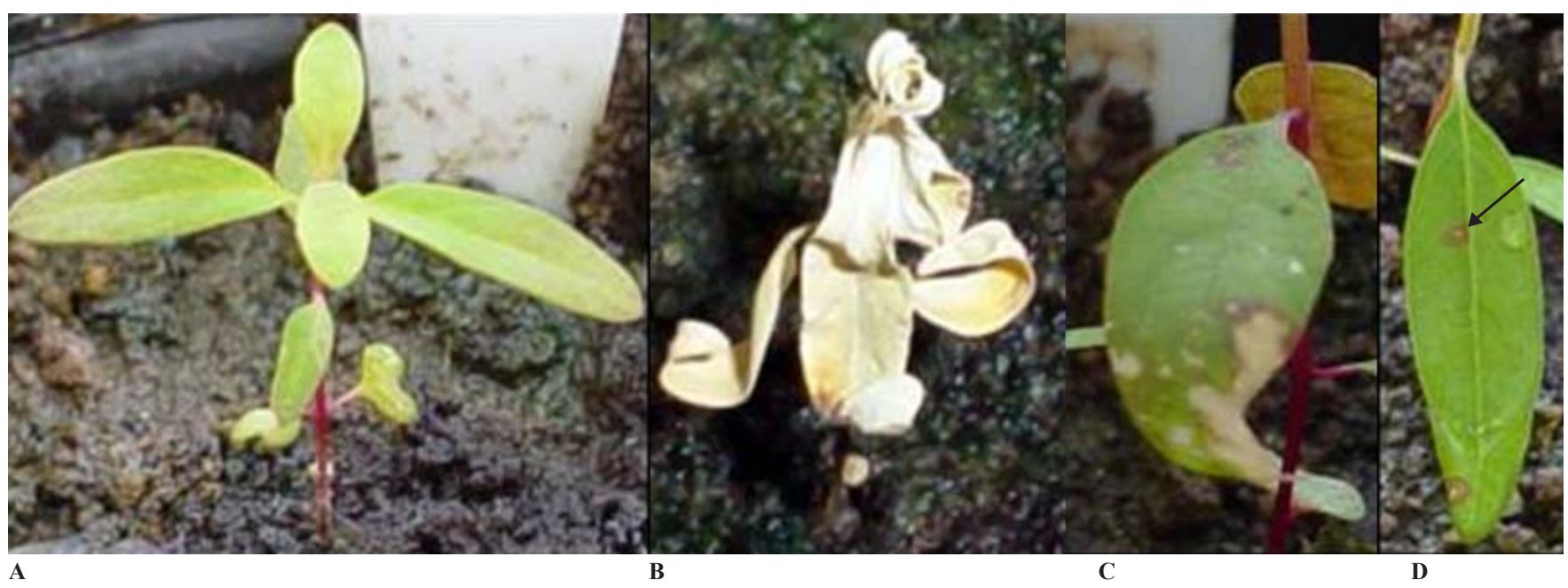

Figura 2 - Sintomas apresentados em diferentes órgãos de Eucalyptus urophylla após as inoculações com isolados de Cylindrocladium. A $\rightarrow$ Controle; $\mathrm{B} \rightarrow$ Morte causada pela inoculação no solo; $\mathrm{C} \rightarrow$ Mancha e necrose do tecido foliar; D $\rightarrow$ Reação de Hipersensibilidade (HR) - seta.

nas dimensões dos conídios (14). Ainda com referência à Tabela 2, deve-se ressaltar que os isolados $\mathrm{Cka}$, obtido da planta ornamental Kalanchoe sp. e o isolado IB328, obtido de eucalipto, foram identificados como pertencentes ao gênero Cylindrocladiella devido às dimensões reduzidas dos conídios. De acordo com Boesewinkel (7) e Crous \& Wingfield (13), o citado gênero agrupa espécies de Cylindrocladium que possuem conídios pequenos.

Comparando-se a morfologia da vesícula terminal e as dimensões dos conídios dos isolados em estudo nos meios BDA, Czapeck e GAA, pôde-se verificar que houve pequena variação nas dimensões dos conídios, porém sem alteração na morfologia das vesículas terminais. Deve-se ressaltar que as alterações ocorridas não modificaram o resultado da identificação dos isolados estudados.

Diferentemente do que se observa em outros gêneros, como por exemplo Colletotrichum (19), existe certa complexidade na correta identificação de isolados do gênero Cylindrocladium através da utilização dos caracteres morfológicos.

\section{Caracterização fisiológica dos isolados}

\section{Patogenicidade dos isolados de Cylindrocladium a diferentes plantas hospedeiras}

Cinco dias após a inoculação das plantas verificou-se que, à exceção de IB515, IB728 e FCA01, os demais isolados mostraram-se patogênicos às folhas de E. urophylla, sendo que IB239, IB328, IB6/ 78, IB12/79, IB17/89, IB01/01 e Cka induziram reação de hipersensibilidade, com alguns isolados produzindo grande número de minúsculas lesões. Os demais isolados resultaram em necrose agressiva do tecido foliar, destacando-se FCA06 e FCA07. A inoculação em solo com os isolados FCA06, FCA07, IB223, IB6/78 e IB12/79 resultou, após seis dias, em lesões no coleto, com posterior murcha e morte das plântulas, que secaram sem tombar (Figura 2 e Tabela 3).

Com relação a $E$. grandis, somente os isolados IB6/78 e IB12/79 provocaram lesões no coleto e morte das plântulas após 4 dias das inoculações no solo. Sobre as folhas do mesmo hospedeiro, somente IB239, IB6/78 e IB12/79 provocaram algumas lesões após 15 dias das inoculações.

Quanto ao lírio-da-paz, somente os isolados IB01/01 e IB238

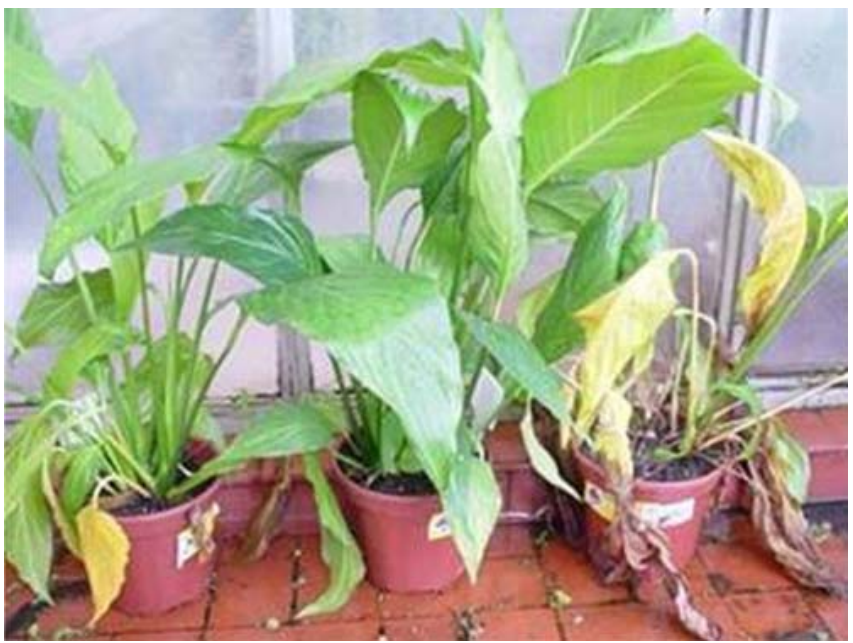

Figura 3. Sintomas apresentados em lírio-da-paz, quando inoculado com Cylindrocladium: A. IB238; B. Controle; C. IB01/01.

induziram sintomas e puderam ser reisolados. Porém, o primeiro mostrou-se mais agressivo, isto por ter provocado sintomas iniciais em curto período de tempo, além de ter provocado a morte das plantas, como é ilustrado pela Figura 3. É importante ressaltar que IB01/01 foi, originalmente, isolado de lírio-da-paz, enquanto que IB238 foi isolado de eucalipto. Comportamento patogênico distinto já foi relatado em inúmeros gêneros, podendo ser citado como exemplo Colletotrichum (22).

Pelo exposto na Tabela 3, verifica-se que existe comportamento patogênico diferenciado dos isolados estudados frente aos diferentes hospedeiros e, também, frente aos diferentes órgãos do mesmo hospedeiro. Observa-se que $E$. grandis foi mais resistente às infecções no coleto e nas folhas. Somente os isolados IB6/78 e IB12/79 foram capazes de infectar o coleto das plântulas de Eucalyptus, reforçando a existência de comportamento patogênico diferencial. Esta característica poderia ser do próprio patógeno ou, apenas do hospedeiro devido a diferente constituição genética ou, mais provavelmente, devido à interação patógeno $\mathrm{x}$ hospedeiro $\mathrm{x}$ ambiente, uma vez que cada um 
Tabela 3. Patogenicidade de Cylindrocladium spp. quando inoculados em diferentes hospedeiros.

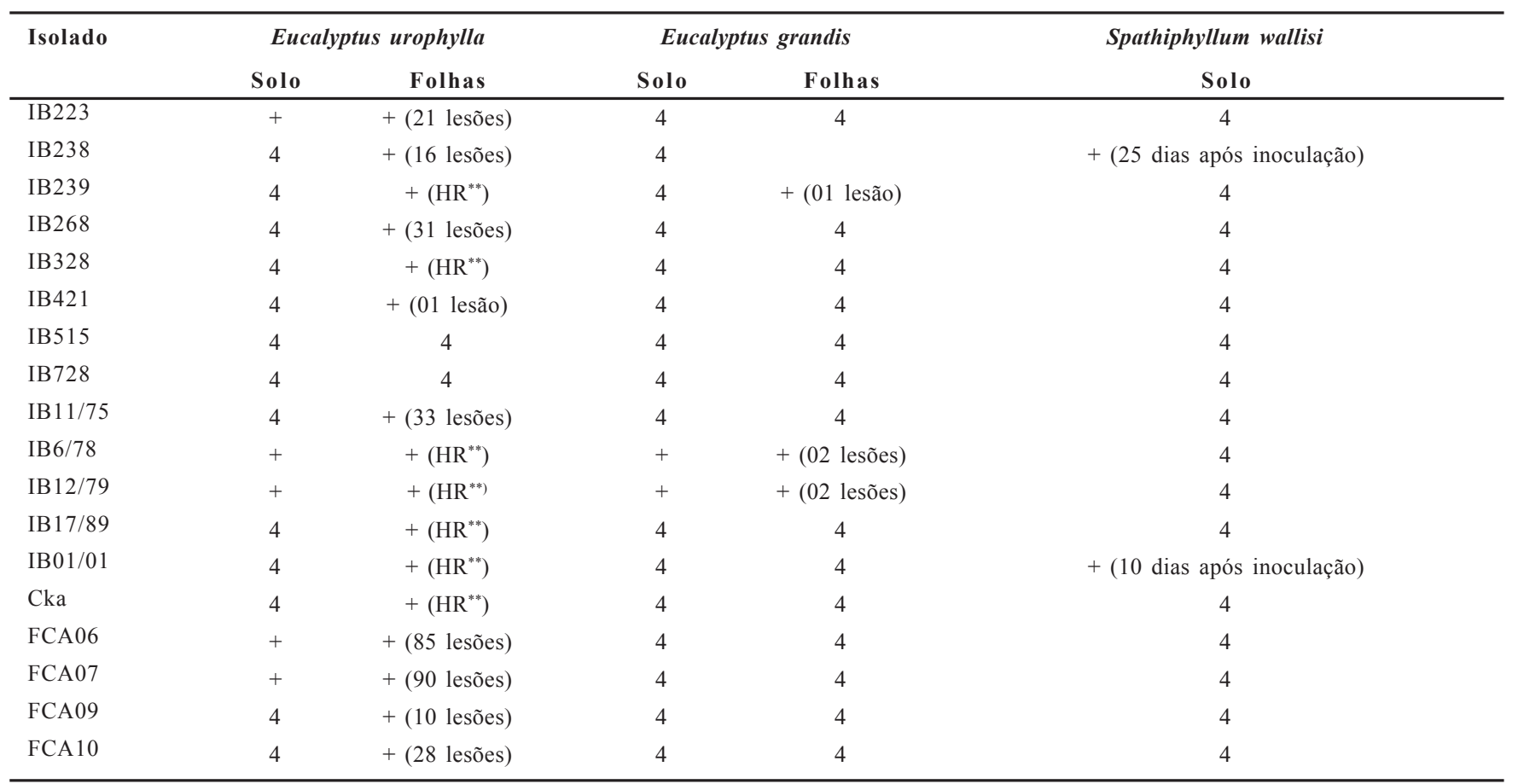

"Média de seis repetições/isolado. / ${ }^{* *} \mathrm{HR}=$ Reação de Hipersensibilidade.

$(-)$ negativo $=$ ausência de sintomas

$(+)$ positivo $=$ ocorrência de sintomas

destes componentes pode influenciar o outro, podendo alterar o grau de severidade da doença.

Foi possível observar, também, uma certa especificidade patógeno $\mathrm{x}$ hospedeiro dentro do gênero Cylindrocladium devido aos resultados obtidos quando o hospedeiro utilizado foi a planta ornamental lírioda-paz. Resultados semelhantes foram relatados por Sobers \& Littrell (36) que, inoculando C. crotalariae, C. scoparium e C. floridanum sobre folhas de amendoim, soja, cevada, aveia e centeio verificaram que, em todos os tratamentos, infecção e sintomas iniciais foram observados 24-48 $\mathrm{h}$ após as inoculações, porém, com maior ou menor grau de severidade. Estes autores concluíram que, embora não tendo sido referidos sobre alguns destes hospedeiros inoculados, estes microrganismos poderiam ser patógenos potenciais.

\section{Coloração das colônias e crescimento em meio Czapeck}

Foi possível a formação de três grupos: Grupo 1-Micélio rasteiro (plano) com coloração variando de castanho-rosado pálido a castanho avermelhado intenso; Grupo 2-Micélio aéreo, com aspecto cotonoso e coloração variando de branco a palidamente róseo; Grupo 3-Micélio aéreo, com aspecto semi-cotonoso e periferia branca e centro castanho claro (Figura 5). Deve-se ressaltar que isolados pertencentes ao Grupo 1 foram patogênicos às folhas e ao colo de plântulas de E. urophylla, sendo alguns dos mais agressivos (FCA06, FCA7 e IB223).

Segundo Rosa \& Menezes (33), a pigmentação e o aspecto da colônia (micélio aéreo ou rasteiro) podem diferir, dependendo do meio de cultura utilizado, de seu $\mathrm{pH}$ e da capacidade do isolado em metabolizar componentes do substrato. Os mesmos autores, estudando alguns isolados de Pseudocercopora musae, observaram crescimento plano do micélio nos meios BDA e V8, com pH 4,5. Nestes mesmos meios, em outros valores de $\mathrm{pH}$, o crescimento do micélio foi aéreo. Com relação à pigmentação, para um mesmo isolado, houve variação em função do meio de cultura utilizado (33). Griffin (23) afirmou que esses pigmentos são, em parte, determinados por fatores genéticos e expressos em função do meio ambiente.

Johnston \& Jones (27) também conseguiram separar isolados do gênero Colletotrichum em 16 grupos distintos com base nas características culturais (cor e aspecto da cultura) desses isolados. Além desses caracteres, a taxa de crescimento da cultura é relatada como possível parâmetro para o agrupamento de isolados (34).

O meio Czapeck possibilitou a diferenciação dos isolados e, conseqüentemente, o agrupamento daqueles com características próximas. Orrego-Fuente et al. (30) obtiveram resultados semelhantes também com isolados de Cylindrocladium, porém não só em meio Czapeck, mas também nos meios de coco, soja e cenoura, os quais induziram à variação nas características culturais dos isolados estudados. Em meio BDA isto não foi possível, uma vez que todos os isolados apresentam o mesmo tipo de micélio (cotonoso), coloração de colônia (marrom-avermelhada intensa) e velocidade de crescimento bem semelhantes. Para Colletotrichum gloeosporioides resultado semelhante em meio BDA foi relatado (34). Devido a não ser um meio de cultura sintético seus constituintes podem apresentar variações, o que pode resultar, para muitos fungos, em uniformidade nas características culturais de diferentes isolados. Ao contrário, os meios sintéticos, como Czapeck, não apresentam variação nas características de seus componentes.

Provavelmente, os constituintes do meio Czapeck, ao serem utilizados pelos isolados para seu desenvolvimento, modificaram a 


\section{GRUPO 1}
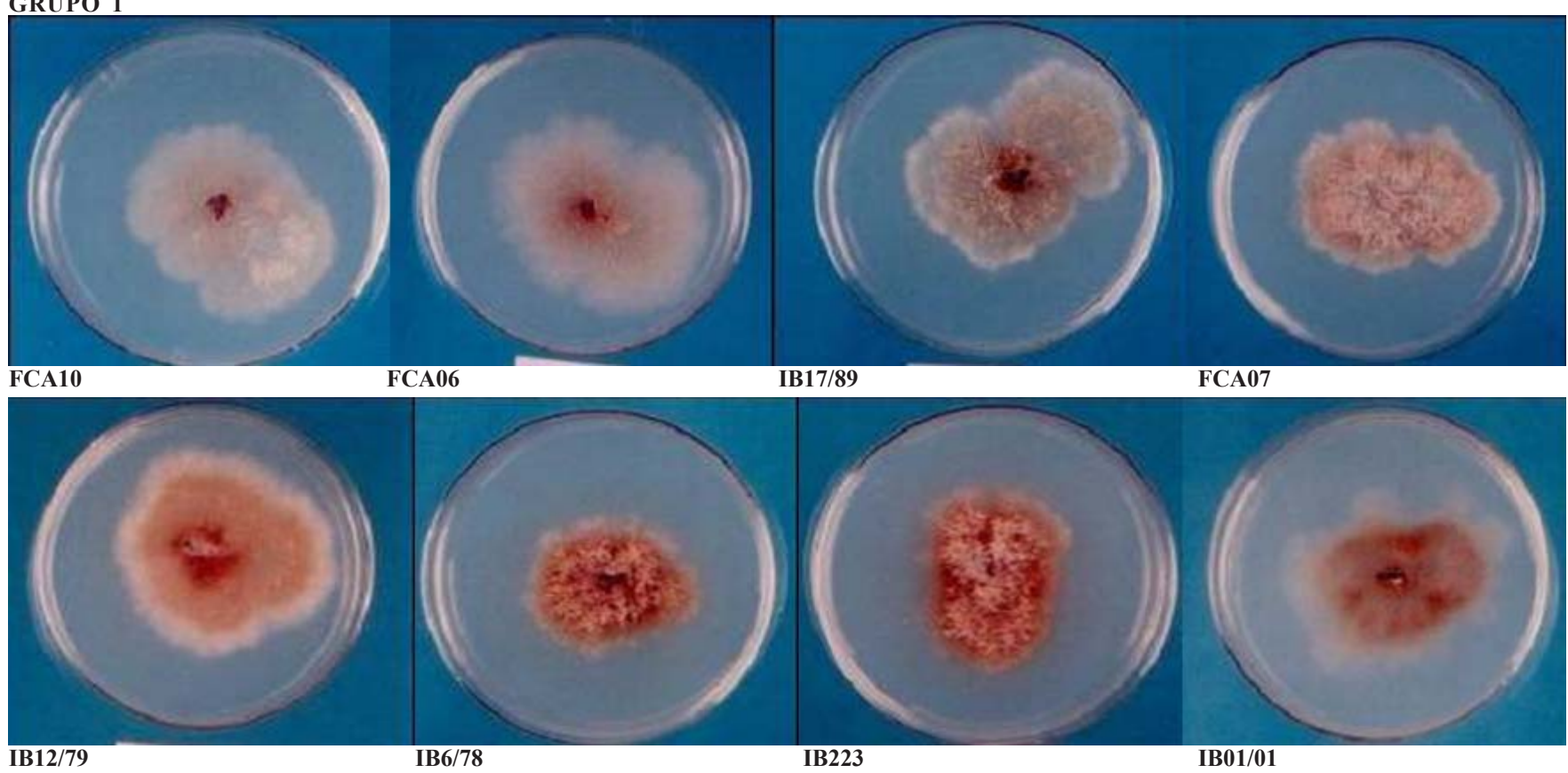

\section{GRUPO 2}

IB6/78

IB223

\section{IB01/01}

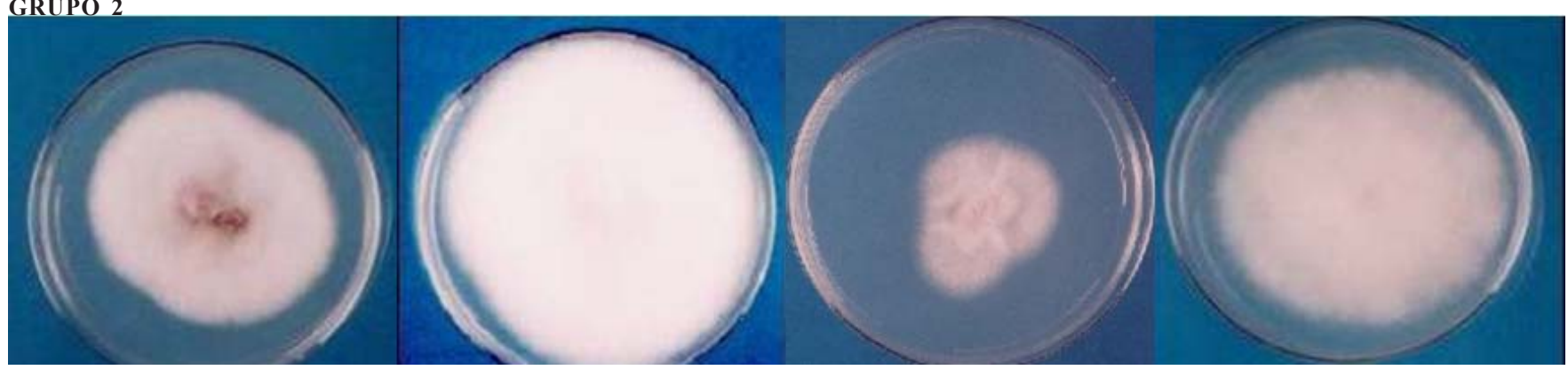

IB239

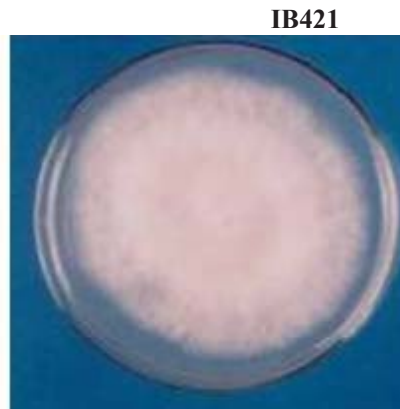

IB328

IB728
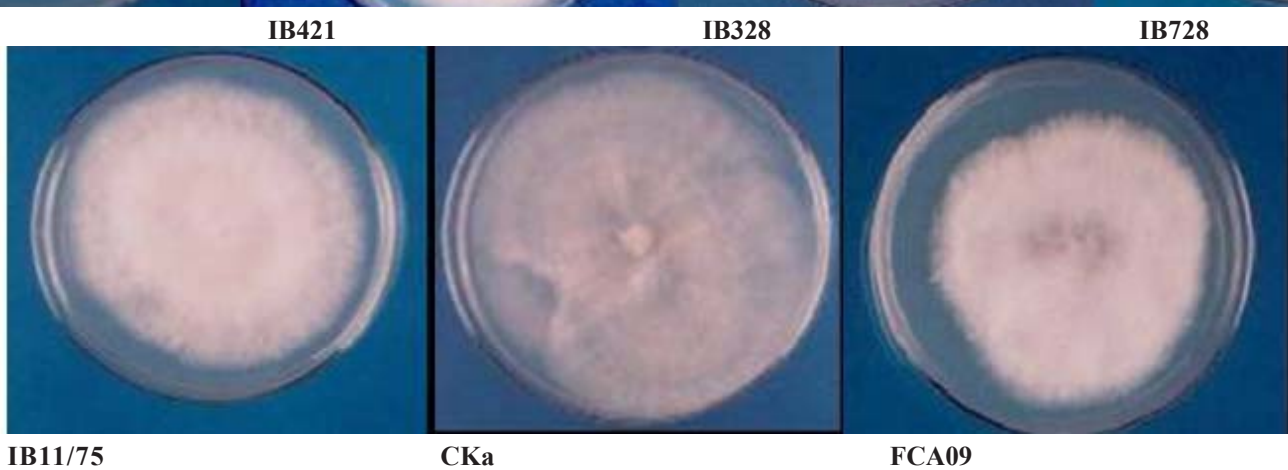

IB $11 / 75$
GRUPO 3

FCA09

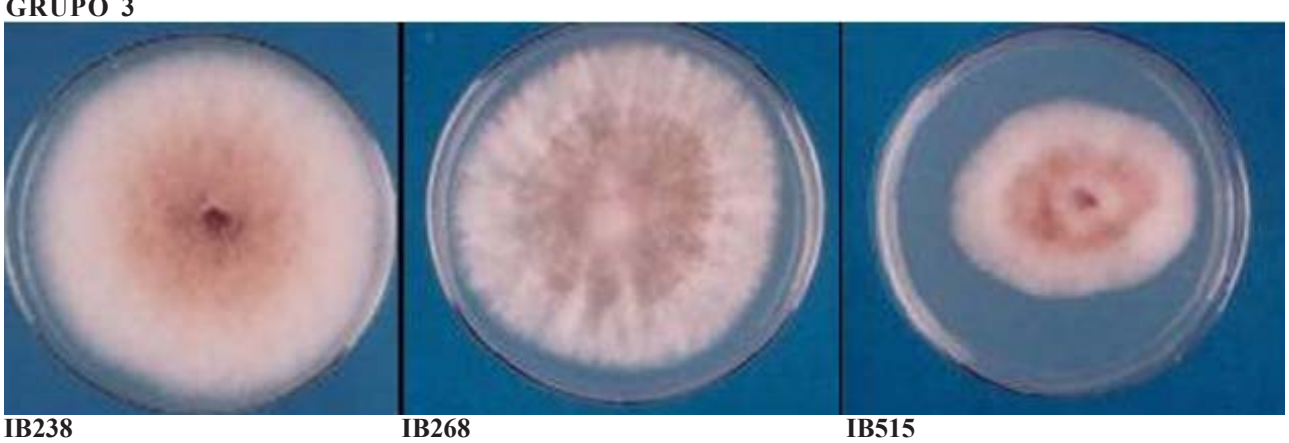

Figura 5. Agrupamento de isolados de Cylindrocladium spp., de acordo com as características de tipo e coloração do micélio e velocidade de crescimento em meio Czapeck. 
Tabela 4. Agrupamento dos isolados de Cylindrocladium spp. cultivados em meio Czapeck, de acordo com o diâmetro e coloração das colônias.

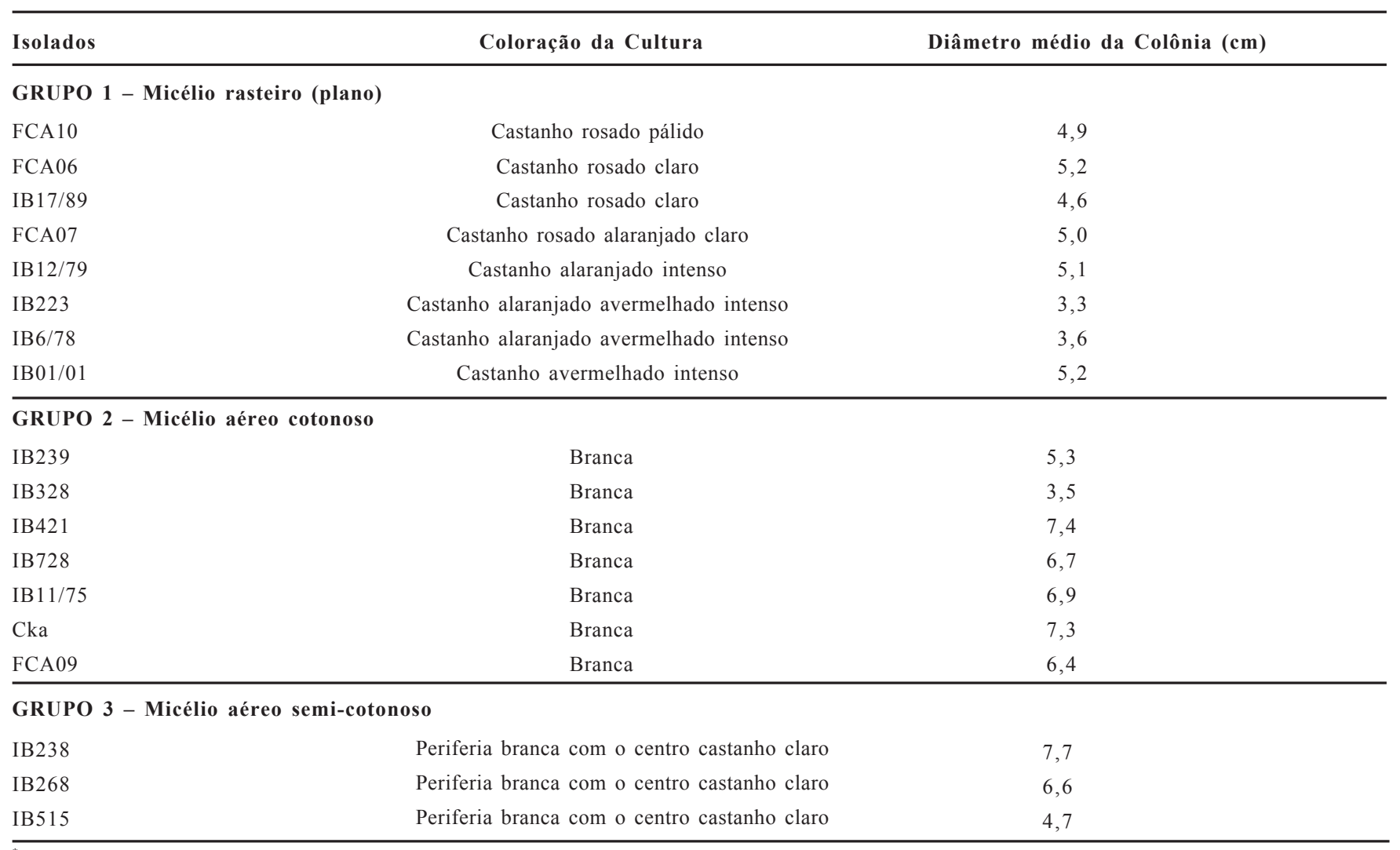

* Avaliação aos 7 dias de idade e temperatura de incubação $=25^{\circ} \mathrm{C}$. Média de seis repetições.

Tabela 5. Diâmetro médio das colônias de isolados do gênero Cylindrocladium, sob diferentes temperaturas, em meio Czapeck.

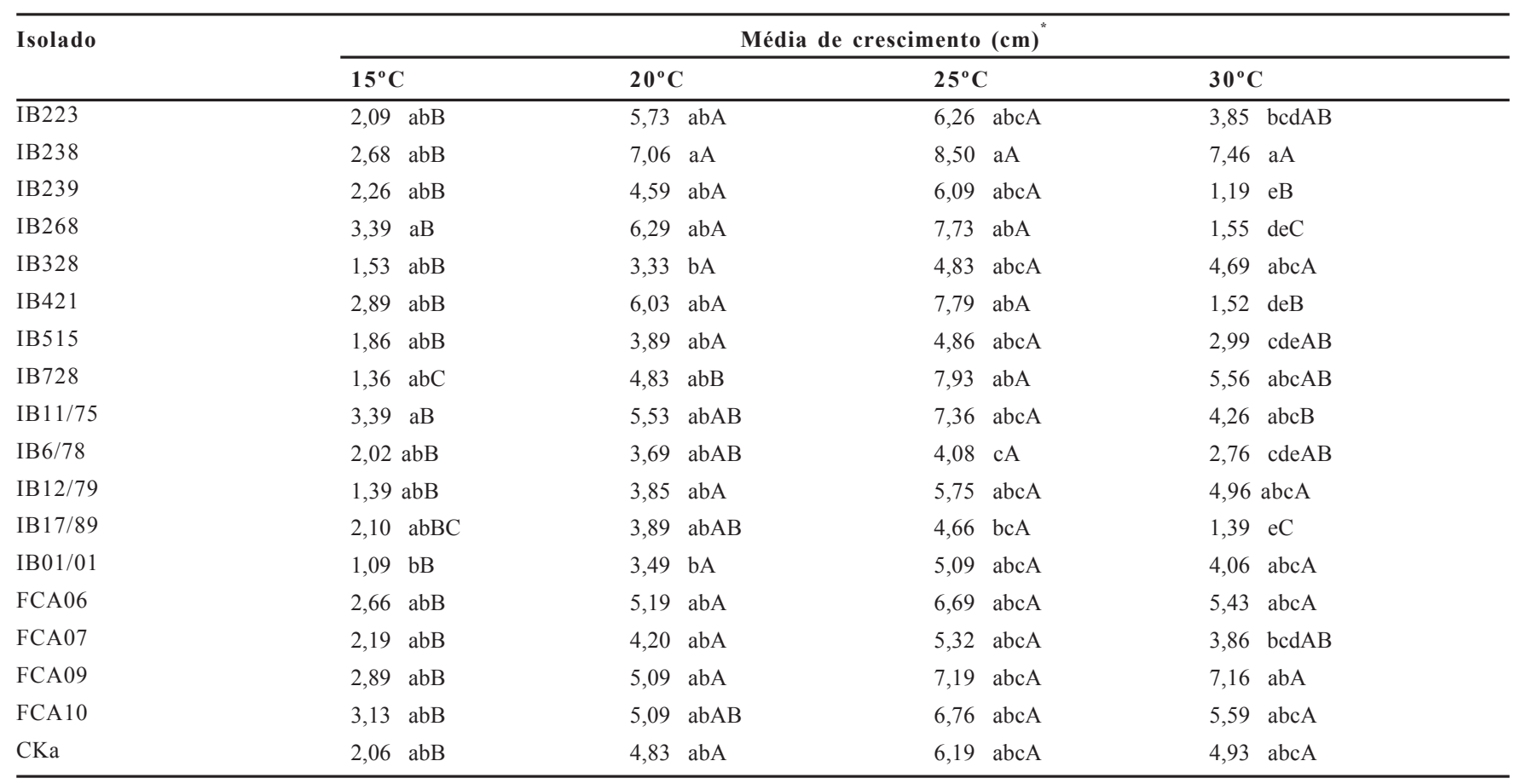

*Médias de três repetições. Para análise estatística os dados forma transformados em $\sqrt{\mathrm{x}}$. Médias seguidas da mesma letra minúscula na vertical e maiúscula na horizontal não diferem entre si pelo teste de TUKEY, ao nível de $5 \%$ de probabilidade. Coeficiente de variação $=12$, $76 \%$. 
fisiologia dos microrganismos, possibilitando a formação diferenciada dos pigmentos das colônias, o que foi refletido nas características morfológicas das culturas. Segundo Cochrane (9), fatores nutricionais como micro-elementos essenciais, fontes de carbono e de nitrogênio podem fazer com que os fungos produzam pigmentos e os liberem no meio de cultura. Castro \& Coelho (8), observaram significativa variação no comportamento de Cercospora cruenta no que se refere ao crescimento micelial quando cultivado em diferentes meios de cultura.

De acordo com a composição do meio, por exemplo, adição de sais $\left(\mathrm{KCl}, \mathrm{NaCl}, \mathrm{NaNO}_{3}\right)$, a morfologia da colônia pode mudar. Os sais podem induzir ao clareamento da colônia uma vez que são nutrientes capazes de interferir na atividade enzimática, metabolismo dos carboidratos, balanço iônico, formação de aminoácidos, nucleotídeos e vitaminas (23). Porém, não se deve menosprezar a capacidade intrínseca do microrganismo em captar e utilizar os nutrientes do substrato suprindo, assim, suas exigências nutricionais $(17,32)$. Tal capacidade pode ser devida aos isolados pertencerem a raças fisiológicas distintas, conforme sugerido por Azevedo (6), e serem diferenciados não pela morfologia, mas somente através de estudos fisiológicos e moleculares. Vechiato (38) também conseguiu diferenciar e agrupar cinqüenta e cinco isolados de Diaporthe phaseolorum var. meridionalis observando crescimento e coloração das colônias nos meios Czapeck e BDA e, Fagan (19), Liyanage et al. (28), Goes \& Kimati (22) e Serra \& Silva (34) conseguiram distinguir "strains" em Colletotrichum acutatum e C. gloeosporioides. Com relação ao crescimento dos isolados, na Tabela 4 está registrado o tamanho, aos sete dias, da colônia de cada um dos isolados. Estes resultados estão de acordo com aqueles relatados por Cochrane (9), ou seja, a velocidade de crescimento varia entre diferentes espécies e, também, entre clones de uma mesma espécie.

Observa-se, portanto, que a maioria dos isolados com comportamento patogênico, coloração da colônia e crescimento micelial semelhantes se encontram no mesmo grupo, conforme registrado na Tabela 5 .

\section{Crescimento dos isolados de Cylindrocladium sob diferentes temperaturas}

Após a avaliação do experimento, pôde-se observar que todos os isolados cresceram a $15^{\circ} \mathrm{C}$, apresentando, porém as menores médias de crescimento. À temperatura de $30^{\circ} \mathrm{C}$, IB239, IB268, IB421 e IB17/ 89 pouco se desenvolveram. Ao contrário dos isolados IB238 e FCA09, que a esta temperatura cresceram bem.

Com relação aos isolados mais agressivos a Eucalyptus urophylla (FCA06 e FCA07), estes apresentaram bom crescimento $30^{\circ} \mathrm{C}$. Pôdese observar, também, que a $25^{\circ} \mathrm{C}$ todos os isolados apresentaram a maior média de crescimento da colônia (Tabela 5), enquanto que a $35^{\circ} \mathrm{C}$, nenhum deles se desenvolveu, sendo esta temperatura considerada letal para todos os isolados estudados.

Embora $25^{\circ} \mathrm{C}$ tenha sido uma temperatura bastante adequada para o crescimento de todos os isolados, pôde-se constatar nítida diferença no crescimento micelial: um dos isolados que mais rapidamente se desenvolveu foi IB238, enquanto um dos mais lentos foi IB6/78. Resultados similares com outros isolados confirmam estes dados (12, $14,15)$.

De acordo com a literatura nacional e internacional observar-se que, para uma mesma espécie, é aceita ampla variabilidade no que se refere à morfologia da vesícula terminal e dimensões dos conídios, o que dificultou a identificação correta das espécies estudadas. Além disso, o comportamento patogênico variável dos isolados frente aos diferentes hospedeiros e frente aos diferentes órgãos do mesmo hospedeiro, torna as espécies desse fungo ainda não referidas como causadoras de doenças sobre plantas importantes, patógenos potenciais. Esta hipótese poderia ser suportada pela provável ocorrência de formae speciales, biótipos ou patótipos de Cylindrocladium.

\section{REFERÊNCIAS BIBLIOGRÁFICAS}

1. Alfenas, A.C. Fungos do gênero Cylindrocladium como patógenos florestais no Brasil. Fitopatologia Brasileira, Brasília, v. 11, p. 275-277, 1986.

2. Alfenas, A.C.; Ferreira, F.A. A mancha da folha de eucalipto no Brasil causada por três espécies de Cylindrocladium - uma revisão da descrição da doença. Revista Árvore, Viçosa, v. 3, p. 4756, 1979.

3. Almeida, O.C.; Bolkan, H.A. Ocorrência e distribuição do gênero Cylindrocladium no Distrito Federal. Fitopatologia Brasileira, Brasília, v. 6, p. 223-228, 1981.

4. Auer, C.G.; Gringoleti Jr, A. Doenças da erva-mate. Summa Phytopathologica, Jaboticabal, v. 21, p. 195-198, 1995.

5. Auer, C.G.; Sotta, E.D. Patogenicidade de Cylindocladium candelabrum em acácia-negra. Boletim de Pesquisa Florestal, Colombo, v. 30/31, p. 29-35, 1995.

6. Azevedo, J.L. Variabilidade em fungos fitopatogênicos. Summa Phytopathologica, Jaboticabal, v. 2, p. 3-15, 1997.

7. Boesewinkel, H.J. Cylindrocladiella, a new genus to accommodate Cylindrocladium_parvum and other small-spored species of Cylindrocladium. Canadian Journal of Botany, Ottawa, v. 60, p. 2288-2294, 1982.

8. Castro, N.R.; Coêlho, R.S.B. Caracterização fisiológica de isolados de Cercospora cruenta em diferentes meios de cultura. Summa Phytopathologica, Jaboticabal, v. 26, n. 4, p. 466-471, 2000 .

9. Cochrane, V. W. Physiology of fungi. New York: J. Wiley, 1958. $542 \mathrm{p}$

10. Coelho, L.; Alfenas, A.C.; Ferreira, F.A. Mancha de folha do eucalipto associada a Cylindrocladium spp e Coniella fragariae. Fitopatologia Brasileira, Brasília, v. 11, p. 380, 1986.

11. Coutinho, L.N.; Aparecido, C.C.; Figueiredo, M.B. Podridão de colo de plantas de lírio da paz (Spathiphyllum wallisii) causada por fungo do gênero Cylindrocladium. Fitopatologia Brasileira, Brasília, v. 26 (Supl.), p. 427, 2001.

12. Crous, P.W. Taxonomy and pathology of Cylindrocladium (Calonectria) and allied genera. St Paul: APS Press. 2002. 278 p.

13. Crous, P.W.; Wingfield, M.J. A re-evaluation of Cylindrocladiella, and a comparison with allied genera. Mycological Research, Cambrige, v. 97, p. 433-448, 1993.

14. Crous, P.W.; Wingfield, M.J. A monograph of Cylindrocladium, including anamorphus of Calonectria. Mycotaxon, Portland, v. 51, p. 341-435, 1994.

15. Crous, P.W.; Phillips, A.J.L.; Wingfield, M.J. Effects of cultural conditions on vesicle and conidium morphology in species of Cylindrocladium and Cylindrocladiella. Mycologia, Albuquerque, v.84, p. 497-504, 1992.

16. Crous, P.W.; Kang, J.C.; Schoch, C.L.; Mchau, G.R.A. Phylogenetic relationships of Cylindrocladium pseudogracile and Cylindrocladium_rumorhae with morfologically similar taxa, based on morphology and DNA sequences of internal transcribed spacers and b-tubulin. Canadian Journal of Botany, Ottawa, v. 77, p. 1813-1820, 1999

17. Ekpo, E.J.A.; Esuruoso, O.F. Factors affecting spore germination in cowpea isolate of Cercospora cruenta Sacc. Phytopathology, St. Paul, v. 67, p. 249-255, 1977.

18. El-Gholl, N.E.; Schubert, T.S.; Walker, S.E. Expanded range of Cylindrocladium colhounii in the United States. Plant_Disease, St. Paul, v. 81, p. 1333, 1997. 
19. Fagan, H.J. Straisn of Colletotrichum gloeosporioides in citrus in Belize. Transactions of the British Mycology Society, London, v. 74, n. 3, p. 643-644, 1980.

20. Figueiredo, M.B.; Cruz, B.P.B. Ocorrência de Cylindrocladium ilicicola (Hawley) Boedijn \& Reitsma sobre Eucalyptus spp. no estado de São Paulo - Brasil. Arquivos do Instituto Biológico, São Paulo, v. 30, p. 29-32, 1963.

21. Figueiredo, M.B.; Namekata, T. Constatação de Calonectria quinqueseptata n. sp., forma perfeita de Cylindrocladium quinqueseptatum Boedijn \& Reitsma, sobre Annona squamosa L. e Eucalyptus sp. Arquivos do Instituto Biológico, São Paulo, v. 34, p. 91-96, 1967.

22. Goes, A. de, Kimati, H. Caracterização patogênica de isolados de Colletotrichum acutatum e C. gloeosporioides obtidos de plantas cítricas. Summa Phytopathologica, Jaboticabal, v. 23, n. 1, p. 10-14, 1997.

23. Griffin, D.H. Fungal Physiology, New York, Jonh Wiley, 1993, v. 2. 458 p.

24. Homechin, M. Avaliação da patogenicidade de três isolados de Cylindrocladium clavatum Hodges e May em árvores de Pinus caribaea Morelet var. hondurensis Barret e Golfari. 1979. 43 p. Dissertação (Mestrado) - Escola Superior de Agricultura "Luis de Queiroz", Universidade de São Paulo, Piracicaba.

25. Hunter, B.B.; Zumpetta, G.M. Differentiating species of Cylindrocladium by acrilamide gel eletroforesis. Proceeding Annual Phytopathology Society, St. Paul, p. 26, 1975.

26. Hunter, B.B.; Barnett, H.L. Growth and sporulation of species and isolates of Cylindrocladium in culture. Mycologia, Albuquerque, v. 70, p. 614-635, 1978.

27. Johnston, P.R.; Jones, D. Relationships among Colletotrichum isolates from fruit-rots assessed using rDNA sequences. Mycologia, Albuquerque , v. 89, p. 420-430, 1997.

28. Liyanage, H.D.; Mcmillian, R.T.; Kistler, H.C. Two genetically distinct populations of Colletotrichum gloeosporioides fom citrus. Phytopathology, St. Paul, v. 82, n. 11, p. 1371-1376, 1992.

29. Metha, Y.R.; Cassetari Neto, D., Cia, E.; Pizzinato, M.A.; Tei- xeira, E.A.; Cunha, H.C. Variabilidade genética entre isolados de Alternaria macrospora do algodoeiro. Summa Phytopathologica, Botucatu, v. 30, n.4, p. 481-487, 2004

30. Orrego Fuente, A.L.; Menezes, M.; Oliveira, S.M.A.; Coelho, R.S.B. Análise comparativa de caracteres patogênicos e físicomorfológicos para identificação de espécies de Cylindrocladium. Summa Phytopahologica, Jaboticabal, v. 22, p. 127-133, 1996.

31. Peerally, A. The classification and phytopathology of Cylindrocladium species. Mycotaxon, Portland, v. 40, p. 323-366, 1991.

32. Queiroz, F.M.; Menezes, M. Efeito de meios de cultura e de regimes de luz no crescimento micelial e esporulação de Cercospora cruenta, agente causal da mancha necrótica do caupi. Revista Omega, Recife, v. 10, p. 36-38, 1997.

33. Rosa, R.T.C., Menezes, M. Caracterização patogênica, fisiológica e morfológica de Peudocercospora musae. Fitopatologia Brasileira, Brasília, v. 26, n. 2, p. 141-147, 2001.

34. Serra, I.M.R. de; Silva. G.S. da. Caracterização morfofisiológica de isolados de Colletotrichum gloeosporioides agentes de antracnose em frutíferas no Maranhão. Summa Phytopahologica, Botucatu, v. 30, n. 4, p. 475-480, 2004.

35. Singleton, L.L.; Mihail, J.D.; Rush, C.M. Methods for research on soilborne phytopathogenic fungi. Minnesota: APS PRESS, 1992.

36. Sobers, E.K.; Littrell, R.H. Pathogenicity of three species of Cylindrocladium to select hosts. Plant Disease Report, Illinois, v. 58, p. 1017-1019, 1974.

37. Tuite, J. Plant pathological methods: Fungi and Bacteria. Minneapolis: Burgess, 1969. 239 p.

38. Vechiato, M.H. Detecção e identificação de Diaporthe phaseolorum var. meridionalis em sementes de soja por PCR 2002. 115 p. Tese (Doutorado) - Faculdade de Ciências Agronômicas, Universidade Estadual Paulista, Botucatu.

39. Watanabe, T.; Hagiwara, S.; Narita, I. Decline of Phellodendron amurense in Tokyo: associated fungi and pathogenicity of associated Cylindrocladium spp. Plant Disease, St. Paul, v. 79, p. 1161-1164, 1995. 